\title{
Da repetição à rasura: Joaquim Manuel Magalhães com Carlos de Oliveira
}

Leonardo Gandolfi

Universidade Federal de São Paulo

$\mathrm{V}$ Tenâncio e Troncho, recém-saídos da cadeia, pelo assassinato de Capula, vagam pela paisagem descampada da gândara "que gerava ladrões, mendigos e assassinos, ganhões e emigrantes, terra mãe enjeitando os seus filhos pelo mundo fora", Venâncio e Troncho "estavam de novo ali, sem trabalho, rejeitados pela desconfiança dos lavradores"1. Até que Troncho pergunta ao outro: “- Onde é que vamos? Pra que é que queres a enxada?"2. Estamos no capítulo final de Alcateia, segundo romance de Carlos de Oliveira.

$\mathrm{Na}$ cena final, eles vão ao cemitério, desenterram seu desafeto, o tal Capula, espécie de duplo dos dois, para com a enxada vingarem-se mais uma vez. Não basta tê-lo assassinado, seria preciso, desenterrado Capula, decepar "a cabeça daquele corpo apodrecido e medonho"'3. Mas enquanto não sabemos disso e diante da pergunta de Troncho, "-Onde é que vamos? Pra que é que queres a enxada?", o narrador diz-nos:

(...) Na perdição em que estava a tombar a sua vida [Venâncio], via-se agora como nunca, para lá do vinho que o turvava, desgraçado e só. Capula ajudara-o a mergulhar

I OLIVEIRA, 1944, p.246.
${ }^{2}$ OLIVEIRA, 1944, p.250.
${ }^{3}$ OLIVEIRA, 1944, p.254. 
mais no abismo, tinha que se vingar de Capula. Mesmo morto, sentia-o ainda a pesar no seu destino. Não podia perdoar. E a ideia súbita que tivera continuava a avolumarse mais e mais. Não podia, que nunca lhe haviam perdoado de si. Querendo vingar-se de Capula, Venâncio nem pensava que se queria vingar afinal da vida, de tudo... ${ }^{4}$

Lemos o trecho citado acima na segunda edição de Alcateia, de 1945. O livro teve sua primeira edição no ano anterior. Com um intervalo tão curto de tempo entre as edições, somos levados a crer no fenômeno de vendas dos livros do jovem Carlos de Oliveira. De fato isso acontecera com o anterior Casa na Duna. Mas o que se passa com Alcateia é bem diferente. Na informação sobre a bibliografia do autor, presente nessa edição, lemos

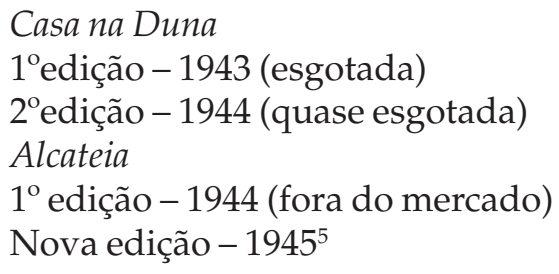

Então, pensando no eufemismo "fora do mercado", volto ao trecho lido, mas extraído agora da primeira edição:

(...) Na perdição em que estava a tombar a sua vida [Venâncio], via-se agora como nunca, para lá do vinho que o turvava, desgraçado e só. Capula ajudara-o a mergulhar mais no abismo, tinha que se vingar de Capula. Mesmo morto, sentia-o ainda a pesar no seu destino. Não podia perdoar. E a ideia súbita que tivera continuava a avolumar-se mais e mais. Não podia, que nunca lhe haviam perdoado de si. Querendo vingar-se

\footnotetext{
${ }^{4}$ OLIVEIRA, 1945, p.246.

${ }^{5}$ OLIVEIRA, 1945, p.2.
} 
de Capula, Venâncio nem pensava que se queria vingar afinal da vida, de tudo, da gente que lhe dera apenas fome e desprezo. Que não era Capula que pesava no seu destino: eram esses, um formigueiro de homens entre escombros dum mundo velho, apunhalando-se pra subsistir, cada um esmagando, antes que os outros o esmagassem. O doutor Carmo, Cosme Sapo, tantos! Esses, que verdadeiramente talhavam a sua sina." 6

A sequência anterior terminava em "que se queria vingar afinal da vida, de tudo...". Na edição "fora do mercado", sabemos então o que de fato designa esse "da vida, de tudo". O alvo de Venâncio era menos um igual a ele como o Capula do que a "gente que lhe dera apenas fome e desprezo", o "doutor Carmo" e outros que "verdadeiramente talhavam sua sina".

É o próprio Oliveira quem disse, mas num livro publicado em 1971: "correcções, rasuras, acrescentos, são o meu forte (e o meu fraco) $)^{\prime 7}$. A reescrita em Oliveira, sobretudo por subtração, é mais do que uma peculiaridade, é um dado a ser lido na medida em que dá uma dinâmica específica à sua obra. E ela acontece de forma deliberada a partir de 1962 na primeira reunião de seus livros de poesia e depois sucessivamente nas reedições de seus romances, Casa na Duna,Pequenos burgueses e Uma abelha na chuva.

No entanto, a primeira vez que Carlos de Oliveira reescreve um livro ocorre em 1944 e de forma não voluntária, ou seja, por ocasião da apreensão do romance Alcateia. A segunda e última edição do livro - de 1945 - é o primeiro texto a ser reescrito pelo autor, não por vontade própria como os demais, mas por imposição da censura. Uma das curiosidades que tal evento criou é que hoje pode ser mais fácil encontrar nos alfarrabistas

\footnotetext{
${ }^{6}$ OLIVEIRA, 1944, p.251.

${ }^{7}$ OLIVEIRA, 2004, p.40.
} 
em Portugal a edição proibida e mais antiga do livro do que a edição que foi comercializada. Justamente porque foi retirada do mercado é que mais exemplares da edição de 1944 encontramse em melhor estado de conservação do que da edição de 1945, exemplares estes manuseados e lidos.

Enfim, a reescrita em sua obra é lida como uma forma de rasurar, recolocar, redimensionar certo tipo de ideologia marxista aplicada ao texto literário, como num primeiro momento o neorrealismo, de forma mais diretiva, exigiu de seus autores. Nessa mesma direção, os vetores do tempo e da memória são dados constitutivos também da obra do autor. A reescrita assim seria uma forma performativa de representação desses vetores na medida em que encena, através da metamorfose dos textos, uma concepção de tempo em que passado, presente e futuro sobrepõem-se materialmente.

Outra curiosidade, se bem que nada dispensável, é o fato de o único livro do autor excluído de sua obra ter sido exatamente Alcateia. Leio, em consonância com essa sobreposição de tempos, a exclusão de Alcateia também como performativa. A reescrita é um mecanismo incorporado aos textos do autor, mas a primeira vez que ele a praticou foi por censura política. Assim é como se, ao praticá-la - numa dinâmica em que textos da década de quarenta podem ser mais novos que outros da década de sessenta -, Oliveira travasse um diálogo estrutural com a censura: a melhor maneira de dizê-la e portanto combatê-la seria assimilando seus mecanismos de proibição, ou seja, jogar com a censura e com a subtração, mas utilizando-as em outro sentido. É o próprio autor de O Aprendiz de Feiticeiro quem escreve: "a realidade cria em si mesma os germes da transformação" ${ }^{\prime}$. Com isso, a reescrita - como emulação do cerceamento e do silenciar - potencializa o compromisso social

${ }^{8}$ OLIVEIRA, 2004, p.65. 
da literatura, ao desenhar um rastro que seria uma forma nova de partilha - palimpsesto que desenha outra narrativa. Pensando nisso, a reescrita - questão de materialidade do texto - não deseja subtrair a participação social, mas torná-la, através da própria subtração, mais performática do que temática.

Penso que o caso de reescrita na obra de Carlos de Oliveira, um caso em que é decisiva a leitura da materialidade do texto, está longe de ser um caso isolado na tradição da moderna literatura portuguesa. Autores fortes como Cesário, Pessanha e Pessoa têm no objeto livro, guardadas as devidas particularidades, uma questão processual. Digo isso na medida em que indeterminação, descontinuidade e incompletude são índices de leitura que atuam decisiva e surpreendentemente na unidade dessas obras. Na verdade, não há grande novidade nisso, porque nunca foi de fato estranho à poesia mobilizar materialmente o texto através, por exemplo, da sonoridade ou da mancha gráfica, mas problematizá-lo materialmente através de versões - em que, como diz Drummond, nunca fica pronta nossa edição convincente ${ }^{9}$ - talvez seja um deslocamento que a partir da modernidade ganhe outros contornos. É pensando nisso - na dimensão material do texto literário que é sobretudo uma dimensão processual - que chego a Joaquim Manuel Magalhães. Não quero correr até seu último livro Um toldo vermelho - em que sua poesia completa é menos rasurada do que substituída -, mas apenas utilizar tal livro como forma de ler a dinâmica da obra deste autor.

Diante de um recorte temporal, acabamos por ler de trás para frente, onde o último ponto da linha, ou seja, aonde por ora chegamos, ajuda-nos a ver de que lugar partimos. A primeira vez em que Magalhães realiza de forma mais radical a reescrita que polemicamente caracterizará sua futura poesia - é um outro

${ }^{9}$ ANDRADE, 1985, p.5. 
momento também polêmico no cenário da poesia portuguesa dos últimos quarenta anos: o tópico do "voltar ao real". Em texto de fins dos anos 70, Joaquim Manuel Magalhães resenha dois livros do poeta António Osório:

No meio de frases destruídas, de cortes de sentidos e de falsas imagens do mundo, organizadas em busca de agressão e de delírio, deixei de saber se a mudança não terá de ser agora um "decorum" novo, um regresso às histórias e às árduas gramáticas sem compêndio. Depois dos efeitos da recusa, se quisermos dizer não, a que diremos não? Que cânones são hoje dominantes contra que se tem de reerguer a triunfante inovação? Voltar a contar de si, voltar ao coração, voltar à ordem das mágoas por uma linguagem limpa, um equilíbrio do que se diz ao que se sente, um respeito pela tradição da língua e dizer a catástrofe pela articulada afirmação das palavras comuns, o abismo pela sujeição às formas directas do murmúrio, o terror pela construída sintaxe dos compêndios. Voltar ao real, a esse desencanto que deixou de cantar, vê-lo na figura sem espelho, na perspectiva quase de ninguém, de um corpo pronto a dizer até às manchas a exacta superfície por que vai, onde se perde. No fundo. ${ }^{10}$

Esse texto foi compilado no livro de ensaios do autor $O s$ dois crepúsculos de 1981. Nesse mesmo ano, Joaquim Manuel Magalhães publica Os dias, pequenos charcos, livro de poemas que se inicia assim:

\section{Princípio}

No meio de frases destruídas, de cortes de sentidos e de falsas imagens do mundo organizadas por agressão ou por delírio

${ }^{10}$ MAGALHÃES, 1981a, p.168. Grifos meus. 
como vou saber se a diferença não há-de ser um pacto novo, um regresso às histórias e às árduas gramáticas da preservação.

Depois dos efeitos de recusa se dissermos não, a que diremos não?

Que cânones são hoje dominantes contra que tem de refazer-se a triunfante inovação?

Voltar junto dos outros, voltar ao coração, voltar à ordem das mágoas por uma linguagem limpa, um equilíbrio do que se diz ao que se sente, um ímpeto ao ritmo da língua e dizer a catástrofe pela articulada afirmação das palavras comuns, o abismo pela sujeição às formas directas do murmúrio, o terror pela construída sintaxe sem compêndios.

Voltar ao real, a esse desencanto que deixou de cantar, vê-lo na figura sem espelho, na perspectiva quase de ninguém, de um corpo pronto a dizer até às manchas a exacta superfície por que vai onde se perde. Em perigo. ${ }^{11}$

O tópico do "regresso ao sentido" - por exemplo, como lido por Fernando Pinto do Amaral a partir de Joaquim Manuel Magalhães - protagoniza um momento especial na recepção crítica da recente poesia portuguesa. Eu gostaria de chamar atenção para a coincidência entre os dois gestos. A nomeação do retorno ao real coincide com a reescrita, se não inaugural,

${ }^{11}$ MAGALHÃES, 1981b, p.13. Grifos meus. 
a mais radical de Joaquim Manuel Magalhães antes de Um toldo vermelho, reescrita que representou o deslocamento de um texto em prosa, parágrafo de uma resenha de jornal, para um texto em versos, poema inicial e programático de um livro de poesia. Ou seja, para voltar ao real como desencanto, ele performativamente volta a algo, que é um outro texto. Repete-o, como se fosse possível a repetição. Carlos de Oliveira prefere a expressão "metamorfoses repetitivas"; diz ele: "É na zona escura do círculo que decorrem as metamorfoses"12. Por falar em Oliveira, tais metamorfoses em Magalhães não acontecem por subtração, como no caso paradigmático de Alcateia, até porque a reescrita agora é sobretudo transcrição e o corte ainda não subtrai, mas sim cria o enjambement. O que está em jogo no transporte realizado do parágrafo para o poema é a descontextualização de um objeto e sua respectiva recontextualização, lógica análoga à do ready made. Assim como Alcateia é um paradigma para o mecanismo da reescrita em Oliveira, acredito que o mesmo aconteça com Magalhães em relação ao poema "Princípio". E penso que esse paralelismo pode nos ajudar a entender as diferenças no funcionamento da reescrita nesses dois autores.

O poeta norte-americano Kenneth Goldsmith, a partir de meados dos anos noventa, vem produzindo uma série de textos etiquetados por ele mesmo como escrita conceitual, procedimento artístico que se aproximaria da arte conceitual do século XX. No prefácio da antologia de escrita conceitual que organizou juntamente com Craig Dworkin, Goldsmith estabelece uma curiosa analogia entre, de um lado, o aparecimento da fotografia e as consequências disso na pintura de fins do século XIX e, de outro, o surgimento da internet e as consequências disso na literatura. Cito-o: "Enquanto a fotografia estava tentando tornar seu foco cada vez mais nítido, a pintura foi forçada a tornar seu traço menos preciso. Diante de

${ }^{12}$ OLIVEIRA, 2004, p.174. 
uma quantidade sem precedentes de textos digitais disponíveis, a escrita precisa se redefinir para viver nesse novo ambiente de excesso de textos"13. E o poeta norte-americano continua: "algo mudou radicalmente: nunca a linguagem teve tanta materialidade, fluidez, plasticidade, maleabilidade - pedindo para ser manuseada ativamente pelo escritor" ${ }^{\prime 14}$. E esse manuseio por parte do escritor, para Goldsmith, está diretamente ligado a um trabalho de corte, colagem e transporte.

Joaquim Manuel Magalhães está muito longe de cortar e colar textos a partir da internet, mas algo do posicionamento de Goldsmith parece-me interessar no trabalho de Magalhães, trata-se, como na arte conceitual, da prática de leitura não só do texto mas também do procedimento. Digo isso para retornar à coincidência do gesto de Magalhães: seu voltar ao real é antes de tudo performativamente um voltar também a outro texto, trata-se da reescrita através, primeiro, da transcrição, segundo, do corte pelo verso, terceiro, da troca de quatro a cinco palavras e expressões, e, por fim, do transporte de um livro de resenhas para um livro de poema. Diferente do poeta norte-americano e outros escritores conceituais, Magalhães recorre à sua própria obra e não repete mais esse procedimento, pelo menos não exatamente desta forma. A questão é que o texto de Magalhães não é apenas o texto em si, mas o deslocamento operado da resenha ao poema: e a leitura do texto é a leitura também desse gesto.

${ }^{13}$ GOLDSMITH, 2011, p.XVII. Minha tradução para:"If photography was striving for sharp focus, painting was forced to go soft, hence impressionism. Faced with an unprecedented amount of available digital text, writing needs to redefine itself to adapt to the new environment of textual abundance."

${ }^{14}$ GOLDSMITH, 2011, p.XXI. Minha tradução para:"something has radically changed: never before has language had so much materiality, fluidity, plasticity, malleability - begging to be actively managed by the writer". 
O poema "Princípio" está fora da reunião do autor de 1987, Alguns livros reunidos, porque na verdade todo o livro Os dias, pequenos charcos está excluído dessa reunião. Em maio de 2001, Magalhães publica Alta Noite em Alta Fraga, em que retoma o texto em questão, mas sem transcrevê-lo ou mesmo (pensado nos termos de Carlos de Oliveira) sem subtraí-lo. Dessa vez ele opta por fazer uma autorreferência, configurando um misto de comentário e desdobramento da própria obra. O poema chamase "Arqueiro" e dele está ausente qualquer tom programático:

Contigo onde a vida terminava ouvi cantar cada pássaro distinto. Enfrentei com firmeza o que é real e fiz dele o teu valor.

$$
\text { Mas ao transpô-lo }
$$

adoecia esse vigor que dera aos versos um ânimo donde partiam. A realidade que se reduz na arte. Embora a torne um reduto que nos cobre de um sossego quase em desabrigo.

Voltar ao real, sim. Como o disse quando outros se refugiavam na linguagem da linguagem.

$$
\text { Nessa altura }
$$

mudaram quase todos de registo.

Mas sempre se esqueceram de que lhe chamei desencanto.

E que tudo nos poemas é suposto excepto quem os escreve.

Embora dentro das palavras eu os recebesse em encantamento, num mundo límpido, à fraude, à ferrugem, à fuligem, à agressão. $(\ldots)^{15}$

${ }^{15}$ MAGALHÃES, 2001, p.69. 
Trata-se de um poema - a começar pelo tom - bem diferente de "Princípio". Busco nele ler o regresso do real e como em Joaquim Manuel Magalhães tal regresso caminha junto não só de uma visão desencantada de mundo, mas também de uma dinâmica processual entre textos. Nos versos de "Princípio", afirma-se: "dizer / a catástrofe pela articulada / afirmação das palavras comuns, / o abismo pela sujeição às formas / directas do murmúrio". Em "Arqueiro", o que se vê é já a recepção encenada ou performativa do poema "Princípio"; "Arqueiro" busca corrigir não o texto anterior - como poderíamos falar da reescrita por subtração em Carlos de Oliveira ou mesmo da própria reescrita por transporte já operada por Magalhães - mas sim corrigir a recepção do texto anterior: "Voltar ao real, sim (...) / Mas sempre se esqueceram de que lhe chamei / desencanto".

Sobre o poema "Princípio", lido como espécie de poética de Magalhães, João Barrento escreve que está “todo ele ponteado pelos sinais da melancolia e pelos códigos da elegia moderna enquanto modo de afirmação estética de uma perda"16. De certa cena poética portuguesa a partir da década de setenta, Fernando Pinto do Amaral diz que o "que sucedeu foi sobretudo uma perda de pathos, um enfraquecimento geral do papel da arte e da poesia, uma relativização de planos ontológicos, acabando tudo isso por permitir que a experiência estética se fosse dessacralizando, embora sem perder um certo brilho de superfície"17. Em termos concretos, o tal "regresso ao sentido", como escreve Amaral ao ler o "voltar ao real" de Magalhães, manifesta-se num contraste com certa poesia anterior mais inclinada, segundo o mesmo crítico, a dar ao poema "um estatuto de um autónomo e quase puro objeto"18. Manifesta-se também, segundo João Barrento, através de uma sensibilidade

${ }^{16}$ BARRENTO, 2006, p.65.

${ }^{17}$ AMARAL, 1988, p.162.

${ }^{18}$ AMARAL, 1988, p.160. 
"mais narrativa e coloquial"19 ou, segundo Eduardo Prado Coelho, transferindo-se "da dimensão mais simbólica para o puro plano da imanência" 20 .

Voltar ao real não implica exatamente um regresso total a uma forma protocolar de realismo. Muito embora possamos ler narratividade, imanência e coloquialidade ou mesmo prosaísmo como índices disso, Rosa Maria Martelo diz tratar-se de "um real totalmente diferente daquele que poderíamos fazer coincidir com um mundo habitual, capaz de produzir um contrato de leitura do tipo realista" ${ }^{21}$. Para ela, o real em desencanto de Magalhães estaria mais próximo "daquele que Lacan fez corresponder à leitura invertida da palavra alemã leer (vazio), o qual, definido pela sua inacessibilidade, nunca facultaria uma contratualização de teor realista - coisa que, no entanto, de modo algum exclui um intenso desejo real"22. Estou longe de discordar de Rosa Maria Martelo, mas acho que o vazio do real segundo Lacan não precisa excluir certo pacto com alguns elementos mais correntes e comunicativos; estes últimos estão presentes em Magalhães, sobretudo, se pensarmos em contraste com os autores que o poeta, provocativamente, chamava dos "outros que se refugiavam / na linguagem da linguagem". Mas, claro, esse pacto é descontínuo, entre outras coisas, até porque, no caso específico de Magalhães, esse pacto colabora para a questão processual onde estão integrados não só narratividade, imanência e coloquialidade, mas também o gesto conceitual da qual a reescrita faz parte.

Em dezembro de 2001, Magalhães mais uma vez revê sua poesia reunida e publica Consequência de lugar, o primeiro de uma série futura de três volumes. Nessa nova reunião há uma nota que diz o seguinte:

\footnotetext{
${ }^{19}$ BARRENTO, 2006, p.66.

${ }^{20}$ Apud BARRENTO, 2006, p.66.

${ }^{21}$ MARTELO, 2010, p.167.

${ }^{22}$ MARTELO, 2010, p.167-168.
} 
Este volume recolhe o conjunto de livros que sinto serem a primeira parte de uma obra que se pôde ir continuando (...). Parece-me que a segunda parte se junta nos volumes publicados entre 1981 e 1993 (...). Enquanto pressinto uma terceira parte iniciada em Alta noite em alta fraga ${ }^{23}$.

O corte para a segunda parte da obra do autor é justamente o livro de 1981, livro que se inicia com a reescrita radical que é o poema "Princípio". Já o poema "Arqueiro", comentário e correção da recepção dos versos de "Princípio", integraria uma terceira parte da obra do autor. Peço atenção às expressões utilizadas por ele: "sinto serem", "parece-me" e "pressinto" para falar da organização futura de sua obra. A publicação em 2010 de Um toldo vermelho confirmaria a hesitação que essas expressões deixam ver. Toda sua poesia é reescrita, no entanto tal reescrita é mais do que rasura e nem mesmo chega a ser subtração. A reescrita é substituição. Narratividade, imanência e coloquialidade, por exemplo, desaparecem. Livros mudam de nome, poemas também. O tom discursivo dá lugar a uma rarefação verbal em textos curtíssimos feitos de parataxe, frases nominais e enumeração. Procuro o poema "Princípio", mesmo estando ausente o livro que ele abre. Faço isto porque uma das seções ou livros de Um toldo vermelho intitula-se "Gaita militar" que recoloca por substituição a sessão "Escritos militares" de Os dias, pequenos charcos; nesta seção, são reconhecidos alguns títulos de poemas deste livro, se bem que não os poemas. Assim, em uma seção intitulada "Traço", escolho seu primeiro texto como uma possível reescrita por substituição do poema "Princípio":

${ }^{23}$ MAGALHÃES, 2001, p.7. 
Apenas o real.

Diferendo. Árduo impacto.

Drenagem vidente.

Atípico e controverso

zarcão.

Superfície e miragem, passaporte. ${ }^{24}$

Retomo Goldsmith, teórico da poesia conceitual: “A legibilidade é a última coisa na mente desse tipo de poesia" 25 . Como leitores, precisamos, diante de Um toldo vermelho, de outro protocolo de leitura. Há uma ruptura radical em relação ao estilo de escrita, mas talvez não haja ruptura tão grande assim em relação à sua obra como questão processual em que o paradigma da reescrita já havia sido posto em prática por meio das três versões anteriores: (1) parágrafo de resenha, (2) poema programático e (3) poema que é leitura da recepção do texto anterior. Essa nova reunião exige a presença fantasmática da obra anterior a ela para ser lida por comparação e, ao mesmo tempo, ela é, nas palavras de Oswaldo Silvestre, a recusa do "melodrama da Poesia Toda, que é aqui substituída pela verdade, um tanto atonal, e para muitos ouvidos insuportavelmente dissonante, da antologia como princípio de construção mas também de destruição" ${ }^{26}$. Se Carlos de Oliveira fizera sumir o livro que disparara seu mecanismo de reescrita, Magalhães faz o mesmo, fazendo desaparecer, porém, toda sua obra.

De volta a Kenneth Goldsmith: "A escrita conceitual só é boa quando a ideia é boa; muitas vezes, a ideia é muito mais

\footnotetext{
${ }^{24}$ MAGALHÃES, 2010, p.67.

${ }^{25}$ Apud PERLOFF, 2013, p.245.

${ }^{26}$ SILVESTRE, 2012.
} 
interessante do que os textos resultantes"27. Ida Alves, ao ler Alta noite em alta fraga, já havia notado em Magalhães - através de imagens recorrentes, entre elas, "valvulina" e "laminagem", por exemplo - uma poesia organizada "entre a ideia de um lubrificante necessário ao movimento de engrenagens de uma máquina e a necessidade de trabalho sobre a matéria para lhe dar forma e espessura"28. Mais uma vez retorno a Goldsmith: "Quando o autor usa uma forma conceitual de escrita, significa que todo o planejamento e as decisões são realizados de antemão, e a execução é um assunto perfunctório. Aideia tornase uma máquina que faz o texto" ${ }^{29}$. Helder Gomes Cancela apontou para tal protocolo conceitual em Um toldo vermelho. Sobre a realização deste, porém, Cancela mostra-se incrédulo: "Talvez isto não seja possível em literatura sem comprometer irremediavelmente a sua identidade: produzir representações verbais que se pretendem do âmbito da literatura implicará uma modelação da linguagem verbal que a retira da simples produção de um projecto conceptual. O saber fazer inerente ao acto de escrita (com o correlativo domínio do medium) ainda constitui critério de qualidade $\mathrm{e}^{\prime 30}$.

Já foram discutidos aqui alguns mecanismos de reescrita que por sua vez estão relacionados diretamente ao objeto livro como questão processual. Faltava apenas falar de qualidade e da falta dela, só para lembrarmos-nos de uma questão crucial na poesia portuguesa dos últimos quinze anos, poesia que tem em Magalhães uma figura tutelar. Nos termos da reescrita segundo o autor de Um toldo vermelho, uma escrita maquinal está mais relacionada ao funcionamento da literatura como processo do que, por exemplo, a modos de impessoalidade

\footnotetext{
${ }^{27}$ Apud PERLOFF, 2013, p.245.

${ }^{28}$ ALVES, 2013, p.25.

${ }^{29}$ Apud PERLOFF, 2013, p.245.

${ }^{30}$ CANCELA, 2010.
} 
caros à modernidade. É por isso que tal escrita lança mão de um "saber fazer" diferente que continua - porém em outros termos - "inerente ao acto de escrita", constituindo um "critério de qualidade" bem diverso. Então leituras como as que falam da afirmação estética de uma perda (João Barrento), da dessacralização da experiência estética (Fernando Pinto do Amaral) e do real como vazio (Rosa Maria Martelo) ganham uma dimensão assustadoramente concreta.

Da mesma forma, a recente e já citadíssima declaração de Jean-Luc Nancy de que a "poesia não coincide consigo mesma" 31 - diante das metamorfoses operadas pelo poeta português - ganha de repente a espessura de uma verdade inteiramente verificável. Por fim, Kenneth Goldsmith fala dos caminhos de uma escrita "mimética e replicadora, em que estão em jogo noções de distribuição e, ao mesmo tempo, novas plataformas de gerenciamento"32. Joaquim Manuel Magalhães - correndo o risco de se tornar mais novo do que os novos que tanto o leram - altera o que chamamos de qualidade ou o que chamamos de falta dela.

${ }^{31}$ NANCY, 2013, p.417.

32 GOLDSMITH, 2011, p.XXI. Tradução minha para: It appears that writing's response will be mimetic and replicative, involving notions of distribution while proposing new platforms of receivership. 


\section{Referências bibliográficas}

ANDRADE, Carlos Drummond de. Corpo. $6^{\circ}$ ed. Rio de Janeiro: Editora Record, 1985.

AMARAL, Fernando Pinto do. “O regresso ao sentido: anos 70/80". In: A Phala-edição especial: um século de poesia. Lisboa: Assírio \& Alvim, 1988.

ALVES, Ida. "Olhares contemporâneos de Sebastião Uchoa Leite e Joaquim Manuel Magalhães". Signótica, v. 25, n. 1, p. 21-33, jan./ jun. 2013. http: / / www.revistas.ufg.br/index.php/sig/article/ view $/ 25713 / 15414$

BARRENTO, João. O arco da palavra. São Paulo: Escrituras, 2006.

CANCELA, Helder Garmes. Joaquim Manuel Magalhães, Um toldo vermelho II. Blog Contra mundum. Publicado em 14/03/2010. http:/ / contramundumcritica.blogspot.com.br/2010/03/joaquim-manuelmagalhaes-um-toldo_14.html Consultado em 20/05/2014.

MAGALHÃES, Joaquim Manuel. Os dois crepúsculos - sobre poesia portuguesa actual e outras crónicas. Lisboa: A regra do jogo, 1981a.

. Os dias, pequenos charcos. Lisboa: Editorial Presença, $1981 \mathrm{~b}$.

. Consequência de lugar. Lisboa: Relógio d'água, 2001.

. Um toldo vermelho. Lisboa, Relógio d'água, 2010.

MARTELO, Rosa Maria. A forma informe. Lisboa: Assírio \& Alvim, 2010.

NANCY, Jean-Luc. Fazer, a poesia. Tradução de Letícia Della Giacoma de França, Janaina Ravagnoni e Mauricio Mendonça Cardozo. Revista Alea. Rio de Janeiro. vol. 15/2, p. 414-422, jul-dez 2013. http:/ / www. scielo.br/pdf/alea/v15n2/10.pdf Consultado em 19/05/2014.

OLIVEIRA, Carlos de. Alcateia. Coimbra: Coimbra editores, 1944.

. Alcateia. Nova edição. Coimbra: Coimbra editores, 1945.

. O aprendiz de feiticeiro. Lisboa: Assírio \& Alvim, 2004.

PERLOFF, Marjorie. O gênio não original - poesia por outros meios no novo século. Tradução de Adriano Scandolara. Belo Horizonte: Editora UFMG, 2013. 
SILVESTRE, Oswaldo Manuel. Na sala de aula: Joaquim Manuel Magalhães (II). Blog Tantas Páginas. Publicado em 04/02/2012. http:/ / tantaspaginas.wordpress.com/2012/02/04/na-sala-de-aulajoaquim-manuel-magalhaes-ii/ Consultado em 18/05/2014.

\section{Resumo}

Primeiro, discutir as diferentes implicações da reescrita poética em Carlos de Oliveira e em Joaquim Manuel Magalhães: de um lado, a reescrita como forma de diálogo necessário com a censura política para, em seguida, se tornar redimensionamento do tempo; do outro, a reescrita como procedimento conceptual em que, em última estância, o procedimento pode ser mais legível que o poema. Por fim, através das versões de um "mesmo" poema de Joaquim Manuel Magalhães, lê-lo da repetição à rasura.

\section{Abstract}

This text, first, discusses the different implications of poetic rewritten in Carlos de Oliveira and Joaquim Manuel Magalhães: on one hand, seen as a way of rewriting the necessary dialogue with political censorship in order to become later another time experience; on the other hand, rewriting as a conceptual procedure where, in the last resort, the procedure may be more legible than the poem. Finally, this text proposes, through versions of the same Joaquim Manuel Magalhães' poem, to read the devices of erasure and repetition. 